\title{
Assembly-Induced Bright-Light Emission from Solution-Processed Platinum(II) Inorganic Polymers
}

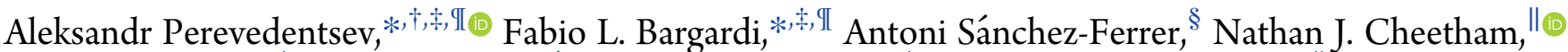 \\ Ahmad Sousaraei, ${ }^{\perp}$ Stephan Busato, ${ }^{\ddagger}$ Johannes Gierschner, ${ }^{\perp}$ (i) Begoña Milián-Medina, ${ }^{\#}$

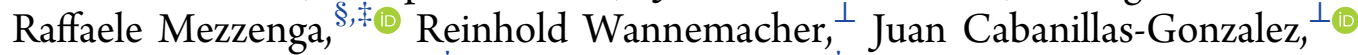 \\ Mariano Campoy-Quiles, ${ }^{\dagger}$ and Walter R. Caseri ${ }^{\ddagger}$ \\ ${ }^{\dagger}$ Institute of Materials Science of Barcelona (ICMAB-CSIC), UAB Campus, Bellaterra 08193, Spain \\ ${ }^{\ddagger}$ Department of Materials, ETH Zürich, Vladimir-Prelog-Weg 5, Zürich 8093, Switzerland \\ ${ }^{\S}$ Department of Health Sciences and Technology, ETH Zürich, Schmelzbergstrasse 9, Zürich 8092, Switzerland \\ "Department of Physics and Centre for Plastic Electronics, Imperial College London, London SW7 2AZ, U.K. \\ ${ }^{\perp}$ Madrid Institute for Advanced Studies (IMDEA-Nanociencia), c/ Faraday 9, Ciudad Universitaria de Cantoblanco, Madrid 28049, \\ Spain \\ \#Department for Physical Chemistry, Faculty of Chemistry, University of Valencia, Avenida Dr. Moliner 50, Burjassot, Valencia \\ 46100, Spain
}

\section{Supporting Information}

ABSTRACT: Synthesis, processing, and characterization are reported for a series of tetracyanoplatinate Magnus' salt (TCN-MS) derivatives-soluble derivatives of the generally intractable Magnus' green salt-that feature the general structure $\left[\mathrm{Pt}\left(\mathrm{NH}_{2} R\right)_{4}\right]\left[\mathrm{Pt}(\mathrm{CN})_{4}\right]$ where $R$ is a branched alkyl group or a $\omega$-phenylalkyl group. In solutions, these coordination compounds generally dissolve on the level of individual ion pairs as shown by X-ray diffraction analysis. To enable the formation of quasi-one-dimensional linear stacks of $\mathrm{Pt}$ (II) atoms in thin films, the matrix-assisted assembly is employed, whereby the compounds are codissolved with poly(ethylene oxide) (PEO), followed by film casting, thermally activated assembly, and eventual removal of PEO. Remarkably, assembled TCNMS inorganic polymers exhibit bright blue-green photoluminescence. A detailed investigation of the assembly process and simultaneously modified solid-state optical properties is performed using a range of microscopy, optical and vibrational spectroscopy, and thermal analysis techniques. Given their unusual
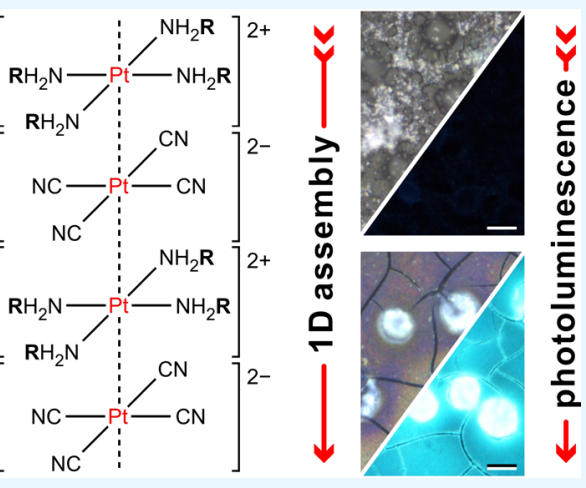
combination of optical properties, namely, transparency in the visible region, high photoluminescence quantum efficiencies (up to $13 \%$ in first-demonstration samples), and large Stokes shifts (up to $1 \mathrm{eV}$ ), TCN-MS derivatives are proposed as a promising class of light-emitting materials for emerging applications in molecular optoelectronics, the potential and challenges of which are discussed.

\section{INTRODUCTION}

Quasi-one-dimensional (1D) arrays of oppositely charged platinum coordination units have been known since the 19th century, the first of which was reported by Magnus ${ }^{1}$ and termed Magnus' green salt (MGS). By 1950s, it was determined that MGS comprises quasi-1D, linear arrays of alternately stacked $\left[\mathrm{Pt}\left(\mathrm{NH}_{3}\right)_{4}\right]\left[\mathrm{PtCl}_{4}\right]$ cation/anion moieties, with adjacent $\mathrm{Pt}$ atoms along the chain separated by $3.25 \AA{ }^{2}$ Notably, this distance is small enough to enable interactions between adjacent platinum atoms. ${ }^{3}$ Recent years have been witnessing a resurgence of research into the optoelectronic properties of Magnus salt-type inorganic polymers ${ }^{4-9}$ following a growing interest within the field of molecular, "plastic" electronics ${ }^{10}$ in the unique properties of organic-inorganic hybrid materials.
The desirable material characteristics for applications in plastic electronics include (i) suitability for rapid, large-area thin-film deposition, (ii) distinctive optical properties such as luminescence or thermo-/solvato-chromism, (iii) high, controllable electrical conductivity, and (iv) stability of optoelectronic properties under ambient conditions. The prototypical materials proposed for plastic electronics applications are based on semiconducting organic polymers, ${ }^{11}$ which, despite their advantages, are typically susceptible to degradation upon exposure to oxygen and water. The emerging classes of organic-inorganic hybrid materials, for example, perov-

Received: April 3, 2019

Accepted: May 28, 2019

Published: June 12, 2019 


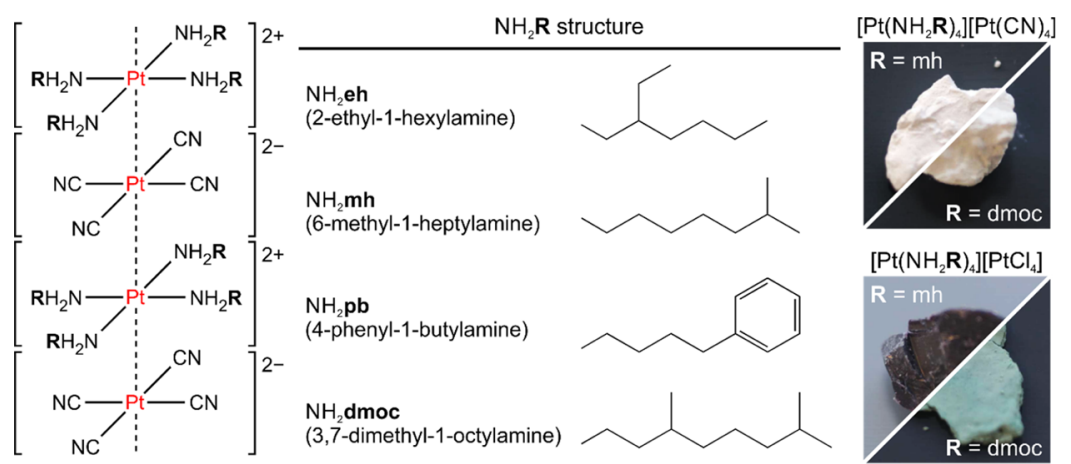

Figure 1. Schematic illustration of the structure of TCN-MS derivatives with the general formula $\left[\mathrm{Pt}\left(\mathrm{NH}_{2} R\right)_{4}\right]\left[\mathrm{Pt}(\mathrm{CN})_{4}\right]$. The different solubilizing side-groups $\mathrm{R}$ are depicted along with the abbreviations used in the text. Also shown are the photographs taken under white-light illumination of the as-synthesized TCN-MS complexes (upper panel) as well as the previously reported (refs 18 and 22) MGS derivatives $\left(\left[\mathrm{Pt}\left(\mathrm{NH}_{2} \mathrm{R}\right)_{4}\right]\left[\mathrm{PtCl}_{4}\right]\right.$; lower panel), with $\mathrm{R}=\mathrm{mh}$ and dmoc in both cases.

skites $^{12,13}$ and metal-organic frameworks, ${ }^{14,15}$ similarly suffer from environmental instabilities as well as nontrivial processing or toxicity of constituent materials. ${ }^{16}$

Returning to Magnus' salt-type platinum(II) inorganic polymers, recent advances in chemical modification of MGS have enabled several of the above-described criteria to be reached. For instance, while MGS is intractable/insoluble, introduction of branched alkyl side-groups $R$ yielded solutionprocessable $\left[\mathrm{Pt}\left(\mathrm{NH}_{2} \mathrm{R}\right)_{4}\right]\left[\mathrm{PtCl}_{4}\right]$ compounds ${ }^{17,18}$ that featured highly anisotropic electronic properties in uniaxially oriented films. ${ }^{5}$ These MGS derivatives also displayed outstanding environmental stability; notably, field-effect transistors comprising $\left[\mathrm{Pt}\left(\mathrm{NH}_{2} \mathrm{R}\right)_{4}\right]\left[\mathrm{PtCl}_{4}\right](R=(S)$-1-amino-3,7-dimethyloctane) as the active semiconducting layer exhibited undiminished device characteristics even following immersion in $90{ }^{\circ} \mathrm{C}$ water for over $12 \mathrm{~h}^{4}$ Electrical conductivity of isotropic polycrystalline films of this material reached $1.6 \times$ $10^{-7} \mathrm{~S} \mathrm{~cm}^{-1}$ with intrinsic hole mobilities exceeding $0.06 \mathrm{~cm}^{2}$ $\mathrm{V}^{-1} \mathrm{~s}^{-1}$.,18

Luminescence has been reported for a small number of Magnus' salt derivatives such as $\left[\mathrm{Pt}(\mathrm{bpy})_{2}\right]\left[\mathrm{Pt}(\mathrm{CN})_{4}\right](\mathrm{bpy}=$ $2,2^{\prime}$-bipyridine, green-yellow spectral region $)^{19}$ and $[\mathrm{Pt}$ (arylisocyanide $\left.)_{4}\right]\left[\mathrm{Pt}(\mathrm{CN})_{4}\right]$ (near-infrared spectral region). ${ }^{20,21}$ The principal interest in these materials has been motivated by their potential applications as sensor materials given their vapochromic characteristics, that is, strong and reversible color changes upon exposure to selected organic compounds. Nevertheless, despite these promising results, to date, these complexes have not been considered as a promising class of light-emitting materials, presumably due to the prohibitively low photoluminescence quantum efficiency (PLQE, 0.2\%) $)^{19}$ obtained for $\left[\mathrm{Pt}(\mathrm{bpy})_{2}\right]\left[\mathrm{Pt}(\mathrm{CN})_{4}\right]$. Furthermore, concerns arise over thin-film deposition of these materials given that they are typically processed from dispersions rather than solutions, with the expected detriment to film homogeneity and reproducibility.

Here, we report the synthesis, processing, and characterization of solution-processable tetracyanoplatinate Magnus' salt (TCN-MS) derivatives featuring the structure $\left[\mathrm{Pt}\left(\mathrm{NH}_{2} \mathrm{R}\right)_{4}\right]$ $\left[\mathrm{Pt}(\mathrm{CN})_{4}\right]$ where $R$ is a solubilizing side-group. Assembly of these coordination compounds into polymeric structures via matrix-based processing is found to enable bright photoluminescence (PL) that furthermore exhibits attractive spectral characteristics, in view of which we advance that TCN-MS derivatives represent a promising next-generation material system for applications in light-emitting devices and plastic electronics.

\section{RESULTS}

Synthesis. TCN-MS derivatives were synthesized using an extension of the method used for the previously reported tetrachloroplatinate complexes with the general formula $\left[\mathrm{Pt}\left(\mathrm{NH}_{2} R\right)_{4}\right]\left[\mathrm{PtCl}_{4}\right]$ where $R$ is an alkyl group. ${ }^{18,22}$ The adopted synthesis route enabled an average yield of $69 \%$, and the resulting compounds were $>99 \%$ pure as determined by the elemental analysis (Table S1).

Figure 1 shows the synthesized coordination compounds. Previous studies of MGS derivatives have demonstrated that, along with enabling solubility, the specific alkyl group $R$ affects both the interplatinum distance and the intrachain order within the quasi-1D polymeric structures via steric effects and the propensity for interligand ordering. ${ }^{6,17,18}$ In particular, it was demonstrated that increasing the number of branching points on the 1-aminoalkyl groups interrupts interligand crystalline packing that adversely affects both chain linearity and interplatinum distance. ${ }^{23}$ Hence, four different $\mathrm{NH}_{2} \mathrm{R}$ ligands were selected (Figure 1) for the study of TCN-MS coordination compounds with the rationale of (i) being sufficiently long to enable solubility ${ }^{17}$ and (ii) featuring $1-2$ branching points or a bulky phenyl group.

As shown in Figure 1, all as-synthesized TCN-MS coordination compounds are colorless, unlike the previously reported tetrachloroplatinate MGS derivatives. This arises from increased crystal field splitting in the former complexes according to the relative positions of the $\mathrm{CN}^{-}$and $\mathrm{Cl}^{-}$ligands in the spectrochemical series, although a difference in the respective interplatinum spacings may also be a contributing factor. 6

For simplicity, the TCN-MS derivatives will be hereafter designated as " $\mathrm{R}-\mathrm{CN}$ " where $\mathrm{R}$ is the abbreviation for the specific ligand of the complex (Figure 1).

Characterization in Solutions. TCN-MS derivatives show optimal solubility in solvents such as $N, N$-dimethylformamide (DMF), dimethyl sulfoxide, and 1-methyl-2-pyrrolidone unlike tetrachloroplatinate MGS derivatives, which are typically dissolved in toluene, $p$-dichlorobenzene, and chloroform. ${ }^{18}$ The infrared (IR) spectra recorded for pristine, assynthesized compounds were found to be identical to the spectra recorded for the same compounds following dissolution in DMF and reprecipitation by evaporation of the 
solvent (Figure S1a). Thus, it is inferred that the complexes are stable and ligand exchange does not take place with DMF, a confirmation of which is obtained by the elemental analysis (Table S2). As a contrary example, applying the same processing to one of the alkyl-substituted tetrachloroplatinate MGS derivatives revealed distinct spectral and chemical composition changes following dissolution in DMF and subsequent isolation (Figure S1b and Table S2). This indicates a decomposition of that complex, for example, by ligand exchange of a chloride ion by a DMF molecule. The observed high stability of TCN-MS derivatives in solvents such as DMF is consistent with the very strong ligand-metal bond expected for the $\mathrm{CN}^{-}$group.

Small-angle X-ray scattering (SAXS) analysis was performed on solutions of TCN-MS derivatives in DMF to investigate the aggregation state of the coordination units. As shown in Figure S2, all SAXS patterns exhibit a (near-)zero slope of scattered intensity as a function of scattering vector $q$ with the exception of pb-CN-likely because of the lower solubility of the latter because of its aromatic 4-phenylbutyl ligands. This implies that no extended Pt(II) stacks are present in solutions in DMF, that is, the coordination units are dissolved on the level of cation/ anion ion pairs or, possibly, individual ions.

To corroborate these observations, SAXS analysis was also performed on the previously reported $\left[\mathrm{Pt}\left(\mathrm{NH}_{2} \mathrm{R}\right)_{4}\right]\left[\mathrm{PtCl}_{4}\right]$ MGS derivatives ${ }^{6}$ dissolved in decalin, revealing the expected presence of rodlike or spherical (i.e., aggregated) objects. As a further proof of concept, dissolution in DMF resulted in decomposition of these tetrachloroplatinate complexes, yielding featureless zero-slope SAXS patterns (Figure S2).

Matrix-Assisted Assembly. Given the inability to meltprocess Magnus' salt derivatives because of the onset of thermal decomposition prior to a melting transition ${ }^{17,18}$ as well as the observations pertaining to the dissolution behavior of TCN-MS derivatives, a novel "matrix-assisted assembly" strategy was devised to enable the ordering of these complexes into quasi-1D, "polymeric" stacks of coordination units within solution-processed thin films.

First, TCN-MS derivatives are codissolved with a small amount of high-molecular-weight poly(ethylene oxide) (PEO; added at 2 wt \% relative to the amount of solvent) in DMF followed by film deposition by spin-coating. Second, following evaporation of the solvent, the films are annealed at a selected temperature-hereafter referred to as the "assembly temperature," $T_{\mathrm{A}}$ - -above the melting temperature of PEO $\left(T_{\mathrm{m}} \approx 70\right.$ $\left.{ }^{\circ} \mathrm{C}\right)$. Thereby, the dissolved TCN-MS coordination units acquire molecular mobility, increasing with $T_{\mathrm{A}}$, and can diffuse within the viscous matrix polymer melt. Given their ionic nature as well as the anisotropic, disklike molecular structure (Figure 1), the TCN-MS coordination units can assemble into quasi-1D stacks, a process which is expected to be driven by electrostatic attraction between adjacent oppositely charged coordination units. Hence, the described matrix-assisted processing applied to TCN-MS derivatives mimics conventional polymerization, whereby the extent of their assembly into macromolecular stacks (i.e., "degree of polymerization") is governed by the molecular mobility of the dissolved coordination units at a given $T_{\mathrm{A}}$. Finally, the films are immersed in water to remove the water-soluble PEO matrix while preserving planar TCN-MS films.

Optical Microscopy. Figure 2 presents optical micrographs of mh- and pb-CN films subjected to varying degrees of assembly, that is, unassembled and assembled at $T_{\mathrm{A}}=150$ and

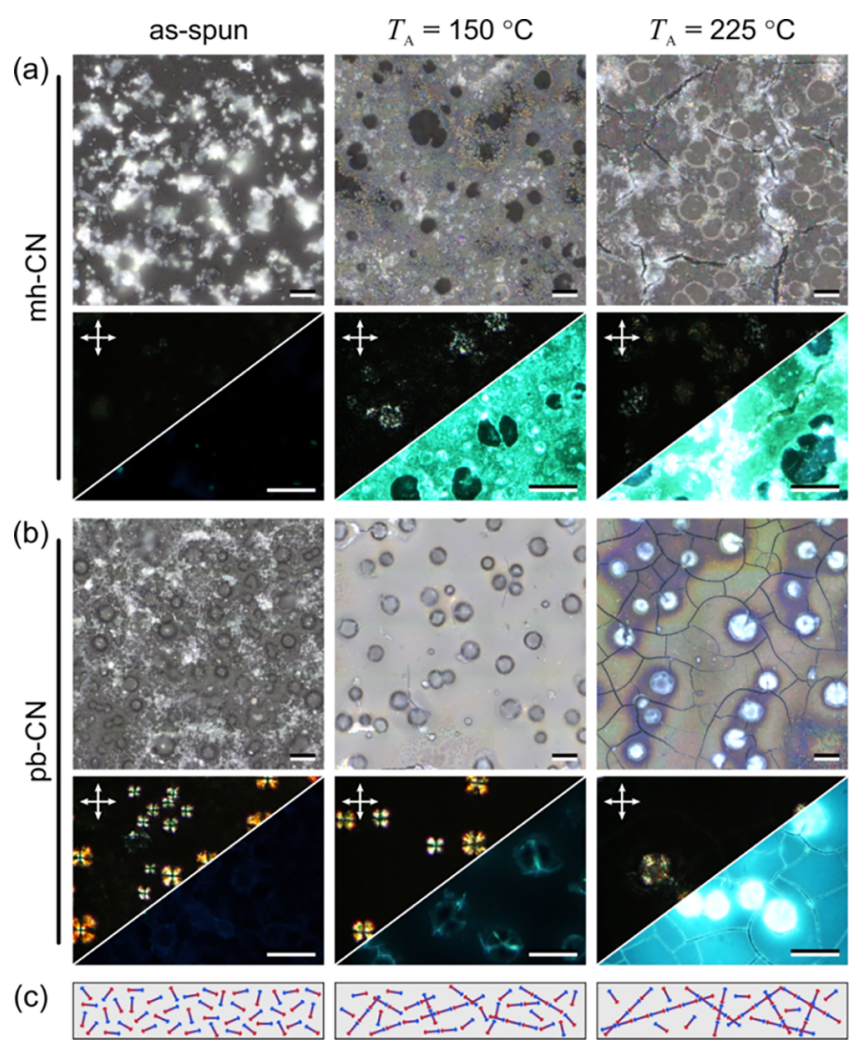

Figure 2. Optical micrographs of (a) mh- and (b) pb-CN films recorded following assembly at selected temperatures, $T_{\mathrm{A}}$, and etching of PEO. Left: as-spun; middle: $T_{\mathrm{A}}=150{ }^{\circ} \mathrm{C}$; right: $T_{\mathrm{A}}=225^{\circ} \mathrm{C}$. Top rows: reflected-light micrographs; bottom rows: cross-polarized transmitted light and fluorescence micrographs (top-left and bottom-right, respectively). Equivalent illumination/imaging settings were used throughout. The scale bar is $25 \mu \mathrm{m}$. (c) Schematic illustration of the assembly process of TCN-MS coordination units (red-blue lines) in PEO (gray) highlighting the progressive "interlinking" of linear TCN-MS polymeric structures that preserves the macroscopic coherence of films following etching of PEO.

$225^{\circ} \mathrm{C}$, followed by etching of PEO. (The corresponding data for dmoc-CN is shown in Figure S3; eh-CN behaves identically to $\mathrm{mh}-\mathrm{CN}$ and will not be analyzed further.) Note that, as will be shown below, $T_{\mathrm{A}}=225{ }^{\circ} \mathrm{C}$ enables maximally complete assembly of TCN-MS complexes without the occurrence of thermal decomposition; hence, films processed at this temperature will be hereafter referred to as "assembled."

Microstructure of the films shows evidence of assembly. Unassembled/as-spin-coated films exhibit patchy substrate coverage because of facile removal of, in essence, smallmolecular TCN-MS material during PEO etching. Annealed films, on the other hand, show progressively more macroscopic substrate coverage with higher $T_{A}$, particularly evident in the case of mh-CN (Figure 2a). This change is attributed to increasingly macroscopic "interlinking" of the films by linear TCN-MS polymeric assemblies, as illustrated schematically in Figure 2c, evoking comparisons with mechanically tough networks of entangled polymer chains as opposed to brittle films of non-inter-connected small-molecular crystals.

Assembled films (Figure 2; $T_{\mathrm{A}}=225{ }^{\circ} \mathrm{C}$ ) exhibit cracks across the surface, the origin of which is ascribed to the swelling stress ${ }^{24}$ applied to rigid (i.e., high glass transition temperature, $T_{\mathrm{g}}$ ) TCN-MS macromolecular network during etching of PEO by immersion in water. To confirm this, a thin 
film of poly (2,4,6-trimethylphenylene methylene $)^{25,26}$ - a lowmolar-mass amorphous polymer featuring $T_{\mathrm{g}}=147^{\circ} \mathrm{C}$-was swelled in acetone, generating a similar crack pattern (Figure S4).

The microstructure of assembled films also indicates phase separation occurring between TCN-MS complexes and PEO during assembly, with flat film areas coexisting with distinct circular/hemispherical regions (hereafter referred to as "bulk" and "aggregated," respectively). Aggregated regions exhibit pronounced birefringence (see cross-polarized micrographs in Figure 2). Phase separation is particularly prominent for $\mathrm{pb}$ $\mathrm{CN}$, which is attributed to (i) the expectation of its lower solubility in the matrix polymer given that its aromatic 4phenylbutyl ligands are less compatible with PEO than the aliphatic 6-methylheptyl ligands of mh-CN and (ii) the abovementioned partial aggregation in solutions, which may give rise to the Maltese cross patterns in the cross-polarized micrographs. In fact, the appearance of assembled pb-CN films is similar to that of phase-separated poly(methyl methacrylate)/poly(styrene-ran-acrylonitrile) (PMMA/SAN) blend films-a widely used material system for studying such phenomena. ${ }^{27,28}$ The physicochemical properties of the matrix polymer are expected to play a determining role here, requiring additional investigation. Further details on phase separationinduced topography of assembled pb-CN films, including scanning electron microscopy and profilometry data, are given in Figure S5.

Remarkably, assembly is also found to simultaneously enable bright blue-green PL for all TCN-MS derivatives with the exception of dmoc-CN (Figures 2a,b and S3). Aggregates show weaker PL relative to the bulk at intermediate degrees of assembly $\left(T_{\mathrm{A}}=150{ }^{\circ} \mathrm{C}\right.$; Figure $\left.2 \mathrm{~b}\right)$, which is consistent with reduced molecular mobility of TCN-MS coordination units in phase-separated PEO-poor regions leading to slower rates of assembly as, in fact, confirmed by Raman spectroscopy (vide infra). Additional high-resolution confocal PL microscopy images highlighting microstructure-dependent PL characteristics are shown in Figures S6-S8.

Optical Spectroscopy. Absorption, PL, and PL excitation (PLE) spectra of the complexes in assembled films $\left(T_{\mathrm{A}}=225\right.$ ${ }^{\circ} \mathrm{C}$ ) as well as solutions in DMF are shown in Figure 3. The absorption spectra in solutions exhibit peaks at 262 and 283 $\mathrm{nm}$, which closely match those of $\mathrm{K}_{2}\left[\mathrm{Pt}(\mathrm{CN})_{4}\right]$ dissolved in water (not shown), albeit featuring a $\sim 5 \mathrm{~nm}$ red shift that is ascribed to the difference in dielectric constants for the two solvents. Given this similarity, as well as by reference to previous reports for MGS derivatives, ${ }^{18}$ these absorption features are assigned to charge-transfer transitions between ligand- and metal-centered orbitals.

Absorption spectra of assembled mh- and pb-CN films exhibit broad, poorly resolved features below $300 \mathrm{~nm}$ (peaks at $\sim 261$ and $292 \mathrm{~nm}$ ). In the case of dmoc-CN, only a single peak at $\sim 268 \mathrm{~nm}$ can be resolved. The absorption edge for all assembled complexes (349-355 $\mathrm{nm}$ for mh- and pb-CN; 324 $\mathrm{nm}$ for dmoc-CN) is found to be strongly red-shifted relative to the solutions. For assembled $\mathrm{mh}-$ and $\mathrm{pb}-\mathrm{CN}$, this redshifted absorption and the residual scattering tail largely obscure the additional, weaker absorption features emerging at $\sim 365$ and $360 \mathrm{~nm}$, respectively, photoexcitation of which yields the PL spectra shown in Figure 3a,b. The PL spectra for both complexes comprise broad bands [full width at halfmaximum $\approx 0.47 \mathrm{eV}$ ] with maxima at 515 and $481 \mathrm{~nm}$ for mhand $\mathrm{pb}-\mathrm{CN}$, respectively, comprising in each case a super-

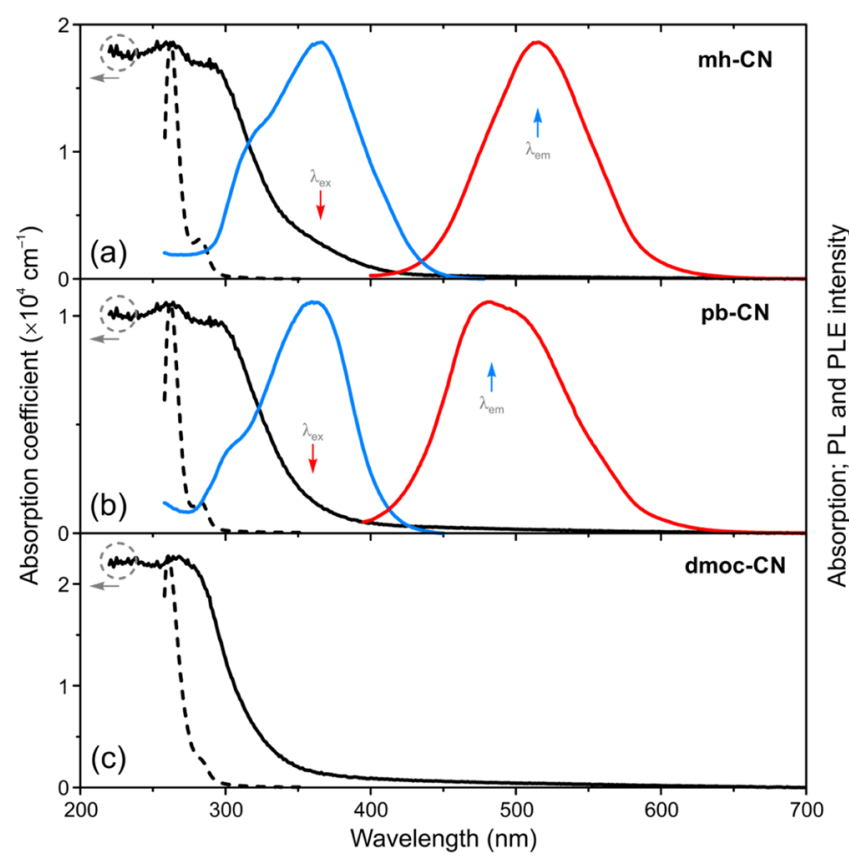

Figure 3. Optical spectroscopy of (a) mh-CN, (b) pb-CN, and (c) dmoc-CN films and solutions. Left ordinate: absorption spectra of assembled $\left(T_{\mathrm{A}}=225{ }^{\circ} \mathrm{C}\right) \mathrm{TCN}-\mathrm{MS}$ films (solid black lines). Right ordinate: peak-normalized PL (red lines) and PLE (blue lines) spectra for the same films, recorded using excitation and emission wavelengths $\left(\lambda_{\mathrm{ex}}\right.$ and $\lambda_{\mathrm{em}}$, respectively) indicated by the arrows. Also shown are the peak-normalized absorption spectra of the respective TCN-MS complexes in $0.2 \mathrm{wt} \%$ solutions in DMF (dashed black lines).

position of two closely spaced peaks. PLE spectra recorded with detection at the respective PL maxima reveal the associated absorption features.

Two further aspects of the spectroscopic properties of assembled TCN-MS derivatives shall be noted at this stage. First, the specific solubilizing group $R$ used as the ligand in the $\left[\mathrm{Pt}\left(\mathrm{NH}_{2} R\right)_{4}\right]^{2+}$ unit appears to affect the PL spectrum (cf. mhand $\mathrm{pb}-\mathrm{CN}$ data in Figure $3 \mathrm{a}, \mathrm{b}$ ) and the overall PL intensity (PL spectrum could not be resolved for dmoc-CN under identical excitation/detection conditions; Figure 3c). Second, the films of all TCN-MS derivatives are virtually transparent across the entire visible spectral range, featuring very large Stokes shifts (0.99 and $0.87 \mathrm{eV}$ for $\mathrm{mh}$ - and pb-CN, respectively) quantified as the difference between PLE and PL spectral maxima.

To further explore the interplay between the matrix-assisted assembly of TCN-MS into quasi-1D polymeric structures and the emergence of luminescent properties, the evolution of relative absorption and PL intensity was analyzed as a function of the degree of assembly as governed by $T_{\mathrm{A}}$. The methodology was adapted from that reported in refs 25 and 29. Blend films of TCN-MS derivatives with PEO were prepared as described above, followed by annealing at incrementally raised $T_{\mathrm{A}}$ for 20 min. Following each annealing step, the equivalent of a PL quantum efficiency (PLQE) spectrum, including both the excitation line and the PL region, was recorded in an integrating-sphere-equipped spectrofluorometer to exclude the effects of changes in light scattering and PL outcoupling. Absorption by the sample is then quantified as the attenuation of the integrated excitation peak area relative to the value for 


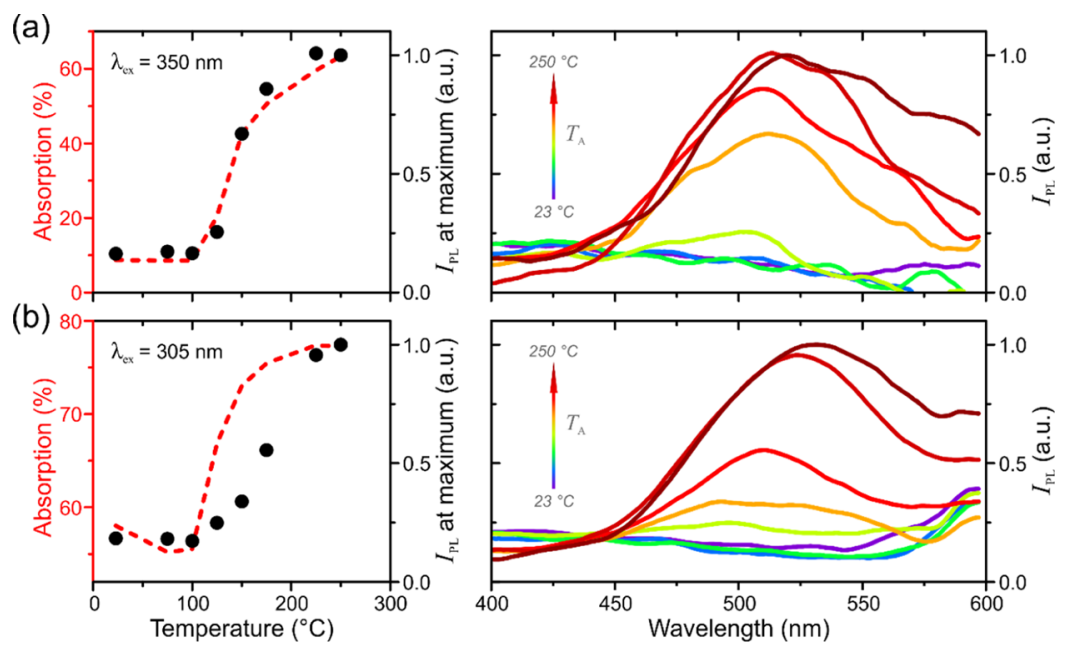

Figure 4. Absorption and PL spectroscopy of mh-CN/PEO blend films during sequential annealing at increasing assembly temperatures. Left panels: Absorption (left ordinate; dashed red lines) and maximum PL intensity in the $450-550 \mathrm{~nm}$ range, $I_{\mathrm{PL}}$ (right ordinate; black circles). Excitation wavelengths, $\lambda_{\text {ex }}$, used are (a) 350 and (b) $305 \mathrm{~nm}$. Right panels: The corresponding PL spectra (adjacent-average smoothing applied). All data are normalized by the respective values at $250{ }^{\circ} \mathrm{C}$.

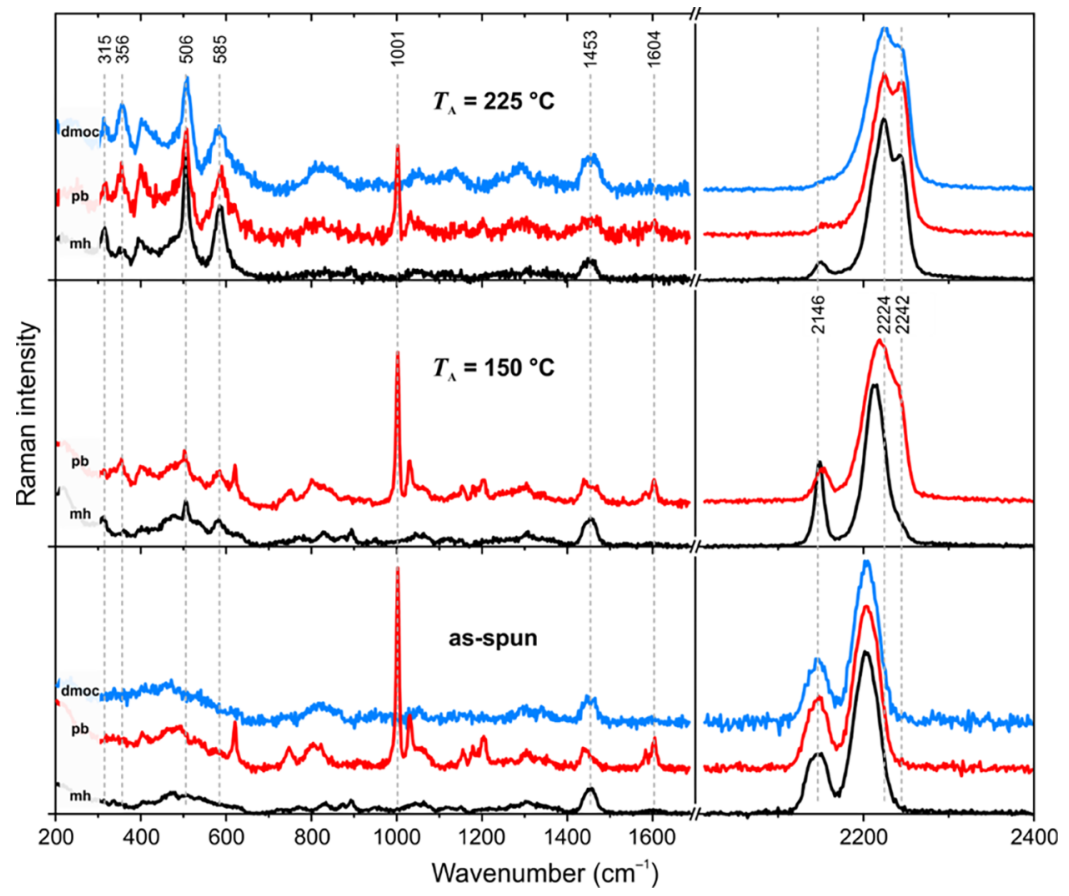

Figure 5. Raman spectra for mh- (black lines), pb- (red lines), and dmoc-CN (blue lines) films recorded following assembly at the indicated $T_{\mathrm{A}}$. Spectra were acquired at the "bulk" locations on the films. All data are peak-normalized by the maximum intensity of the $v(\mathrm{C} \equiv \mathrm{N})$ mode $(\sim 2200$ $\mathrm{cm}^{-1}$ ), with different ordinate scaling in the left and right panels adopted for clarity. The spectral positions of selected peaks are also shown.

an uncoated substrate. The value for the maximum intensity in the 450-550 nm PL spectral region is also extracted.

The representative data for mh-CN is shown in Figure 4, wherein absorption and PL intensity are found to follow a sigmoidal profile with increasing $T_{\mathrm{A}}$, as is commonly observed for an amorphous solid/solution to crystal transformation process. $^{29,30}$ Exciting close to the peak of the PLE spectrum $\left(\lambda_{\mathrm{ex}}=350 \mathrm{~nm}\right.$; Figure $\left.4 \mathrm{a}\right)$ results in a correlated increase of absorption and PL intensity with an onset at $\sim 100{ }^{\circ} \mathrm{C}$ and a plateau at $\sim 225{ }^{\circ} \mathrm{C}$. On the contrary, exciting at the lowwavelength edge of the PLE spectrum $\left(\lambda_{\mathrm{ex}}=305 \mathrm{~nm}\right.$; Figure $4 \mathrm{~b})$ leads to delayed emergence of PL (i.e., higher onset temperature) relative to absorption increase. From this difference, we infer that energy transfer plays a contributing role in populating the emitting state-a process that is inhibited at intermediate/incomplete assembly $\left(T_{\mathrm{A}}<200^{\circ} \mathrm{C}\right)$.

Raman Spectroscopy. Figure 5 shows the Raman spectra recorded for films of TCN-MS derivatives, previously analyzed in Figure 2, exhibiting different degrees of assembly via $T_{\mathrm{A}}$ selection. For a given $T_{A}$, the Raman spectra for all three studied TCN-MS derivatives show a close match, with the exception of the modes specific to the $\mathrm{NH}_{2} \mathrm{R}$ ligands used (see Table S3 for assignment of vibrational modes).

In all cases, the most prominent spectral features correspond to the stretching mode of the cyanide groups. Unassembled/ as-spun films exhibit a weak peak at $2146 \mathrm{~cm}^{-1}$ and a sharp 
intense peak at $2203 \mathrm{~cm}^{-1}$. Multiple energies for cyanide group vibrations have also been reported for crystals of tetracyanoplatinates of the form $M_{x}\left[\mathrm{Pt}(\mathrm{CN})_{4}\right] \cdot y \mathrm{H}_{2} \mathrm{O}$ and were attributed to heterogeneities in the dielectric environment and the crystallographic location of these groups. ${ }^{31}$ Following assembly at $T_{\mathrm{A}}=225{ }^{\circ} \mathrm{C}$, both peaks harden to 2151 and $2224 \mathrm{~cm}^{-1}$, respectively, with an additional peak appearing at $2244 \mathrm{~cm}^{-1}$. Such mode hardening is generally attributed to increased intermolecular interaction as, for instance, observed for polymers under high hydrostatic pressure ${ }^{32}$ and is therefore consistent with densification of the material upon ordering. Interestingly, however, the energy of $\mathrm{C} \equiv \mathrm{N}$ stretching vibrations in the assembled TCN-MS derivatives is significantly higher than generally reported for cyanoplatinate crystals, for example, by $61 \mathrm{~cm}^{-1}$ compared with $\mathrm{Rb}_{1.75}[\mathrm{Pt}$ $\left.(\mathrm{CN})_{4}\right] \cdot 1.25 \mathrm{H}_{2} \mathrm{O}^{31}$ A proposed explanation for this will be outlined in the following section.

Assembly of TCN-MS derivatives is accompanied by increased intensity and narrowing of the peaks in the 315$585 \mathrm{~cm}^{-1}$ region, which corresponds to $\mathrm{Pt}-\mathrm{C}$ and $\mathrm{Pt}-\mathrm{CN}$ stretching and bending vibrations. Such changes are indicative of an increasingly homogeneous dielectric environment within assembled, quasi-1D polymeric structures. Elsewhere, comparison of Raman spectra recorded at "bulk" and "aggregated" locations (Figure S9) corroborates the observation of inhibited/delayed assembly and, hence, emergence of PL in the aggregated regions (see $T_{\mathrm{A}}=150{ }^{\circ} \mathrm{C}$ data in Figure 2).

Finally we point out that, while all three studied TCN-MS derivatives appear to exhibit the spectroscopic signatures of assembly, the films of assembled dmoc-CN are negligibly luminescent, unlike mh- and pb-CN (Figure 3). This is likely to be related to the structure of the solubilizing side-groups for dmoc-CN (Figure 1), which prevent favorable ordering between adjacent coordination units required for the formation of the corresponding electronic state, although previous reports for tetrachloroplatinate MGS derivatives indicated that steric repulsion plays a minor role. ${ }^{6}$

Thermal Analysis. The final confirmation of matrixassisted assembly of TCN-MS derivatives was obtained using differential scanning calorimetry (DSC) analysis. Solvent-free powder mixtures of selected TCN-MS compounds and PEO (3:1 wt/wt ratio) were dissolved by heating to $75^{\circ} \mathrm{C}$ (slightly above $T_{\mathrm{m}}$ of PEO), and following equilibration for $30 \mathrm{~min}$, they were rapidly heated to an elevated temperature to initiate assembly.

Figure 6a shows the data for the pb-CN/PEO mixture. Following rapid heating to $145{ }^{\circ} \mathrm{C}$, an exothermal signal is observed, corresponding to assembly/crystallization of $\mathrm{pb}-\mathrm{CN}$. Given that this process takes place at a constant temperature, the data can be analyzed using the well-known Avrami equation $^{30,33}$ that describes phase transformation kinetics under isothermal conditions. Gratifyingly, the conventional linear fit to the data is obtained for low ( $\leq 3 \%)$ degrees of transformation $X$ in the Avrami plot shown in Figure $6 \mathrm{~b}$. The gradient of the fit represents the Avrami exponent, $n_{A}$, which corresponds to a specific nucleation type and crystal growth geometry. The obtained value of $n_{\mathrm{A}}=2$ is indicative of sporadic nucleation and $1 \mathrm{D}$ crystal growth ${ }^{33}$ and is therefore fully consistent with the assembly of individual TCN-MS coordination units into quasi-1D polymeric structures.

Intrachain Structure. At this stage, we turn our attention to the intrachain structure of TCN-MS assemblies and the nature of bonding therein. Density functional theory (DFT)
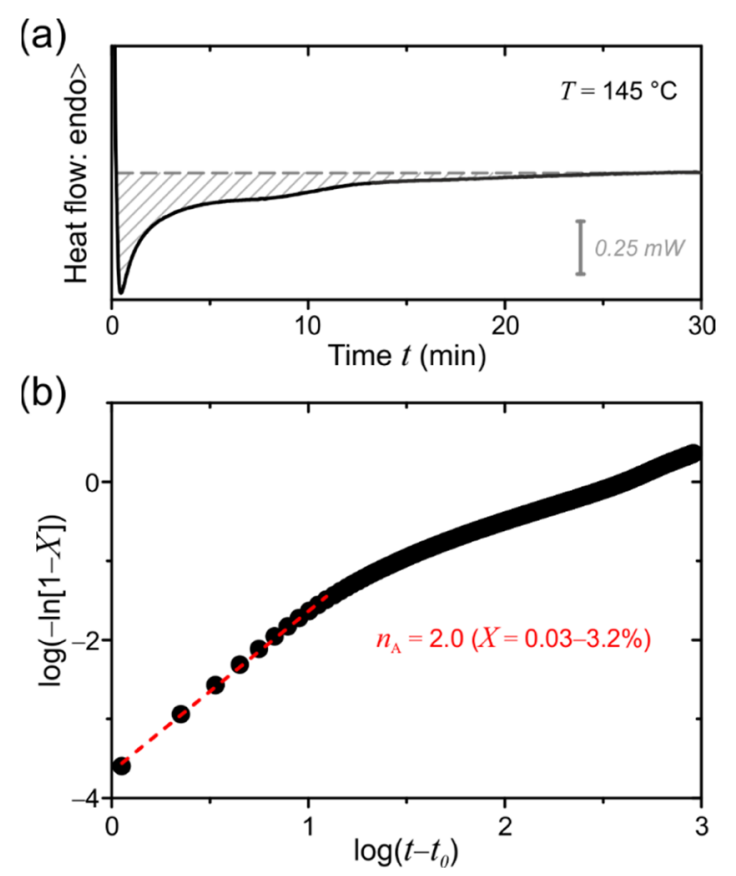

Figure 6. (a) Isothermal crystallization thermogram recorded for $\mathrm{pb}$ $\mathrm{CN}$ in a 3:1 wt/wt solution with PEO following rapid heating to 145 ${ }^{\circ} \mathrm{C}$ at time $t=0$. Dashed line indicates the zero baseline. (b) Avrami plot for the data shown in (a). Experimental data $(\bullet)$ was fitted using the Avrami equation for $X=0.03-3.2 \%$, where $X$ is the relative degree of transformation and $t_{0}$ is the induction time. The Avrami exponent, $n_{\mathrm{A}}$, corresponding to the gradient of the linear fit is indicated.

calculations were performed for $\left[\mathrm{Pt}\left(\mathrm{NH}_{2} R\right)_{4}\right]\left[\mathrm{Pt}(\mathrm{CN})_{4}\right]_{n}$, where $\mathrm{R}=\mathrm{CH}_{3}$ and $n$ is the number of cation/anion pairs in the coordination stack, to obtain geometry-optimized structures. While this is clearly a simplified compound compared with the studied TCN-MS derivatives and may omit the potentially relevant steric effects, it nevertheless provides several important insights. Selected results are shown in Figure $7 \mathrm{a}$ and the detailed structural data is compiled in Table S4.

For dimers $(n=1)$, the Pt...Pt distance between oppositely charged coordination units is found to be 3.30 A . Interestingly, the geometry-optimized structure in Figure 7 a obtains the $\mathrm{Pt}-$ $\mathrm{C} \equiv \mathrm{N}$ angle $=166^{\circ}$, which deviates from the expected squareplanar arrangement. While such a feature has not been previously reported for related $\mathrm{Pt}(\mathrm{II})$ complexes, here it is preliminarily ascribed to the partial charge transfer in the electronic ground state, as can be readily seen in the electronic surface potentials (Figure 7a). This is further manifested in a considerable twist between adjacent Pt-centered ions, with the staggering angle $\theta(\mathrm{N}-\mathrm{Pt}-\mathrm{Pt}-\mathrm{C})=26^{\circ}$ and a remarkably small separation between the nitrogen atom of the $\mathrm{C} \equiv \mathrm{N}$ group and the hydrogen atom of the $\mathrm{NH}_{2} \mathrm{CH}_{3}$ group, $d\left(\mathrm{~N}_{\text {cyanide }} \cdots \mathrm{H}_{\text {amine }}\right)=2.02 \AA$. Note that this distance is much smaller than the sum of the respective van der Waals radii $(2.75 \AA)$ and is therefore indicative of a strong interaction between the two moieties.

For $n=8$ stack (Figure $7 \mathrm{a}$ ), the Pt...Pt distance reduces to $3.27 \AA$, approaching the respective value for MGS of $3.25 \AA^{2}{ }^{2}$ Both $\left[\mathrm{Pt}\left(\mathrm{NH}_{2} \mathrm{CH}_{3}\right)_{4}\right]^{2+}$ and $\left[\mathrm{Pt}(\mathrm{CN})_{4}\right]^{2-}$ units in the center of the stack are planar because of symmetric electronic interactions with the neighboring units. $d\left(\mathrm{~N}_{\text {cyanide }} \cdots \mathrm{H}_{\text {amine }}\right)$ exhibits a minor elongation to $2.39 \AA$. 
(a)

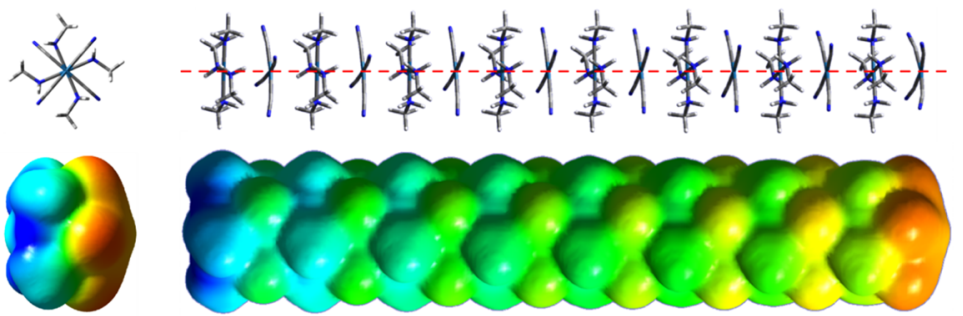

(b)

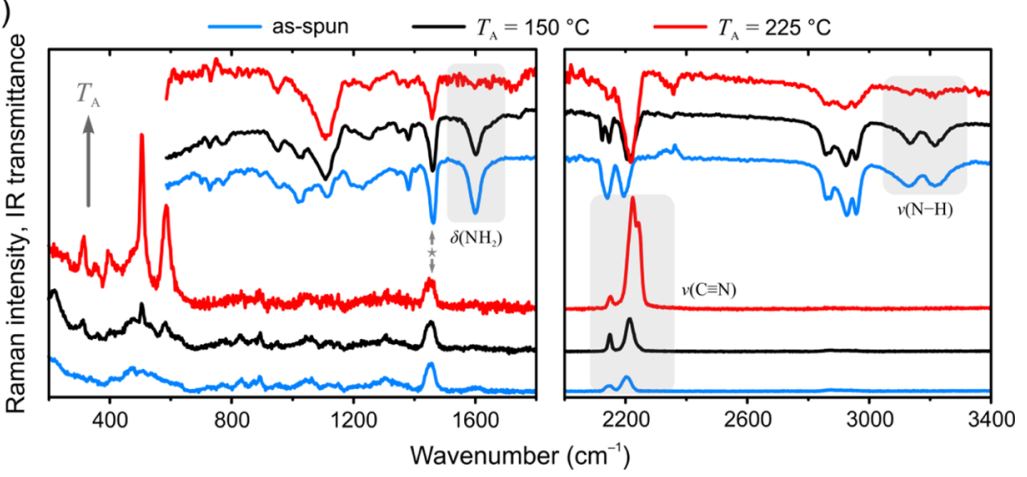

Figure 7. (a) DFT-optimized structures and electronic surface potentials for $\left[\mathrm{Pt}\left(\mathrm{NH}_{2} \mathrm{CH}_{3}\right)_{4}\right]\left[\mathrm{Pt}(\mathrm{CN})_{4}\right]_{n}$-a methyl-substituted TCN-MS derivative-where $\mathrm{n}$ is the number of cation/anion pairs. Data is shown for $n=1$ (left; top and side views) and $n=8$ (right; side views). (b) Raman and IR spectra (lower and upper parts of the panels, respectively) for mh-CN films recorded following assembly at the indicated $T_{\mathrm{A}}$. Raman spectra were acquired at the "bulk" locations on the films. All data are peak-normalized by the $1453 \mathrm{~cm}^{-1}$ peak (indicated by starred arrow) corresponding to the aliphatic ligands. Different ordinate scaling in the left and right panels is adopted for clarity. Gray boxes highlight selected spectral changes upon assembly.

Further insight into intrachain bonding can be gained by comparing the IR and Raman vibrational spectra for different degrees of assembly. Figure $7 \mathrm{~b}$ shows the representative data for mh-CN films (Figures 2 and 5) normalized by the 1453 $\mathrm{cm}^{-1}$ peak (alkyl bending vibrations), the relative intensity and position of which are expected to be largely invariant with the degree of assembly. Of particular note are the relative changes in the intensity of specific vibrational modes as well as the previously discussed changes in the vibration energies. Specifically, the relative intensity of the $\mathrm{C} \equiv \mathrm{N}$ stretching modes undergoes a 7-fold increase upon assembly (see Raman data in Figure 7b). Simultaneously, the intensities of the $\mathrm{N}-\mathrm{H}$ stretching and $\mathrm{NH}_{2}$ stretching/bending modes (see IR data in Figure $7 \mathrm{~b}$ and Table S5) exhibit a 5-6-fold decrease. Note that the disappearance of amine vibrations cannot be ascribed to thermal cleaving of $\mathrm{NH}_{2} \mathrm{R}$ ligands because the characteristic vibrations of the alkyl substituents $R$ are invariably observed.

While, undeniably, further analysis will be required to understand the origins of this behavior, we advance a preliminary explanation based on electrostatic, hydrogenbonding-type interaction between the nitrogen atoms (of the $\mathrm{CN}$ group) with a negative partial charge and a hydrogen atom (of the adjacent $\mathrm{NH}_{2} \mathrm{R}$ group) with a positive partial charge. In the case of MGS, the occurrence of hydrogen bonding between $\mathrm{NH}$ groups and the adjacent Pt-bound chlorides was postulated following DFT calculations, ${ }^{8}$ which revealed the corresponding $\mathrm{H}_{\text {amine }} \cdots \mathrm{Cl}$ distance to be substantially smaller than the sum of the respective van der Waals radii. (N.B. As described above, a similar observation is also made for TCNMS derivatives-see Table S4.)

The typical vibrational spectroscopy signatures of hydrogen bonding include (i) reduced intensity and (ii) decreased vibrational mode energies for the participating groups, which are ascribed to bond elongation and the accompanying decrease of interatomic force constants. ${ }^{34,35}$ However, the opposite is observed for the $\mathrm{C} \equiv \mathrm{N}$ stretching mode of TCNMS derivatives following assembly (Figure $7 \mathrm{~b}$ ). This can be rationalized when considering the particular geometry of the assembled 1D polymeric structure (see schematic illustration in Figure S10). The nitrogen atoms of sp-hybridized CN groups are located at a farther distance from the $\mathrm{Pt}$ chain axis than the hydrogen atoms of the $\mathrm{sp}^{3}$-hybridized $\mathrm{NH}_{2} R$ groups. Consequently, the electrostatic attraction between partially negative $\mathrm{N}_{\text {cyanide }}$ atoms and partially positive $\mathrm{H}_{\mathrm{NH}_{2} R}$ atoms would, in fact, increase the interatomic force constant for $\mathrm{C} \equiv \mathrm{N}$ vibrations, resulting in the observed increase in intensity and energy of the $\mathrm{C} \equiv \mathrm{N}$ stretching vibrations upon assembly (Figure $7 \mathrm{~b}$ ). The proposed reasons for the disappearance of $\mathrm{NH}$ vibrations in the IR spectra upon assembly are more subtle and are likely to be related to the increased symmetry within the polymeric structure. For example, in high-symmetry smallmolecular systems such as hydrogen-bonded cyclic dimers of $\varepsilon$ caprolactam, the rule of mutual exclusion applies, causing, in that case, only the symmetric, Raman-active $\mathrm{C}=\mathrm{O}$ stretching mode to be observable. ${ }^{34}$

The interpretation above, although preliminary, helps to reconcile several observations, namely, (i) multiple $\mathrm{C} \equiv \mathrm{N}$ stretching modes exhibiting unusually high energies, (ii) preferential solubility of TCN-MS derivatives in polar aprotic solvents such as DMF, and (iii) $\mathrm{Pt}-\mathrm{C} \equiv \mathrm{N}$ angle $<180^{\circ}$ in the DFT-optimized structure of $\left[\mathrm{Pt}\left(\mathrm{NH}_{2} \mathrm{CH}_{3}\right)_{4}\right]\left[\mathrm{Pt}(\mathrm{CN})_{4}\right]$ dimers.

Nucleated Assembly. Looking ahead, further optimization of matrix-assisted assembly and, therewith, the microstructure and optical properties of TCN-MS derivatives will be required for their applications in optoelectronic devices. Here, we present a proof-of-concept demonstration of the use of nucleating agents for achieving this goal. 
Films of mh- and pb-CN were processed from two sets of solutions: (i) as above and (ii) containing 2 wt \% 1,3:2,4-bis(3,4-dimethyl benzylidene)sorbitol (DMDBS) - a widely-used commercial "nucleating/clarifying agent" ${ }^{36}$-relative to the amount of TCN-MS in solution. Solutions were deposited under identical conditions followed by assembly at $T_{\mathrm{A}}=225$ ${ }^{\circ} \mathrm{C}$ and etching of PEO.

Figure 8 shows the optical micrographs of the resulting films. In the case of mh-CN, nucleation by DMDBS is found to
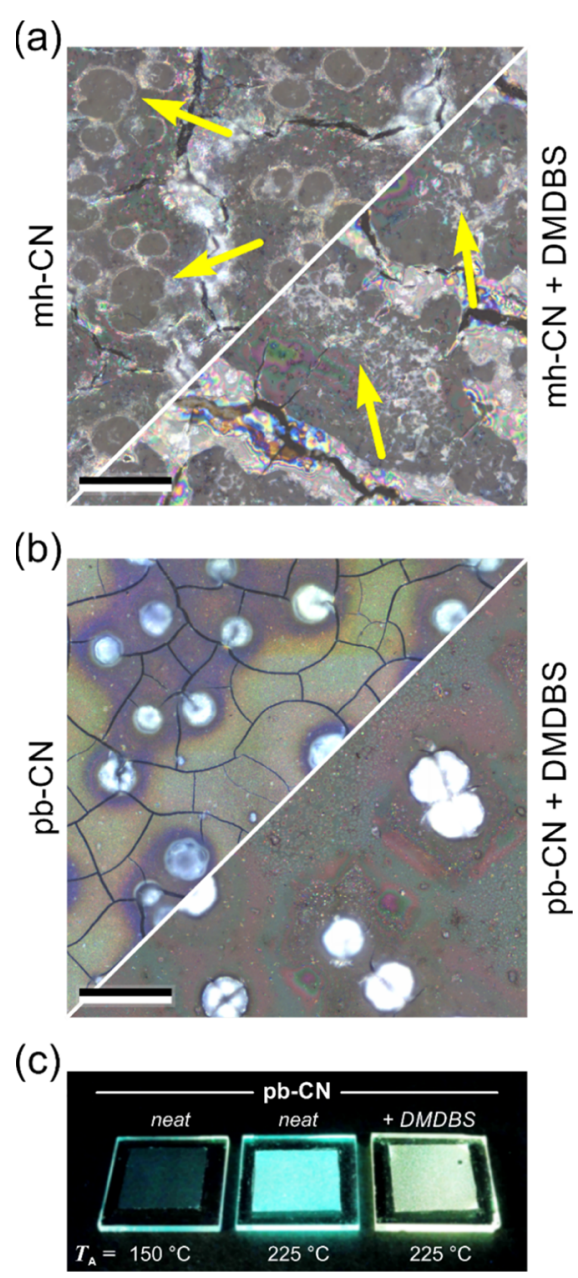

Figure 8. Effect of the DMDBS nucleating agent on the microstructure and PL of TCN-MS films, showing reflected-light micrographs of assembled (a) mh-CN and (b) pb-CN films. Films were processed from solutions without DMDBS (top-left panels) and with 2 wt \% DMDBS added relative to TCN-MS (bottom-right panels). The scale bar is $50 \mu \mathrm{m}$. The arrows in (a) highlight the characteristic features that are modified upon addition of DMDBS. (c) Photograph of $\mathrm{pb}$-CN films under UV light illumination, with the corresponding $T_{\mathrm{A}}$ and compositions indicated.

reduce the degree of phase separation, preventing the formation of circular domains (as indicated by the arrows in Figure 8a) by, most likely, initiating crystallization/assembly prior to the occurrence of coarse phase separation. An important consequence of this is the disappearance of weakly luminescent dark spots for the nucleated films (Figures $2 \mathrm{a}$ and S11).

In the case of pb-CN, DMDBS-nucleated assembly is found to prevent the formation of microcracks in the resulting films (Figure $8 b$ ) - a desirable feature for incorporation of TCN-MS derivatives into multilayer thin-film devices. Given the high melting temperature of DMDBS, it is unlikely to function as a plasticizer; hence, the improved mechanical coherence of the nucleated films is ascribed to a more pronounced interlinking of the films by elongated stacks of pb-CN coordination units. Interestingly, nucleation by DMDBS is simultaneously found to change the PL color of assembled pb-CN from blue-green (neat films) to green-yellow (nucleated films) as shown in Figure $8 \mathrm{c}$. To the best of our knowledge, this is the first report of light emission characteristics of macromolecular materials modified via the use of nucleating agents, presenting an interesting avenue for future research.

Optical Properties. Additional optical characteristics of TCN-MS derivatives that are of particular relevance to their application in light-emitting devices are analyzed and summarized in Table 1.

Table 1. Summary of Selected Optical Properties of Assembled $\left(T_{\mathrm{A}}=225^{\circ} \mathrm{C}\right) \mathrm{TCN}-\mathrm{MS}$ Films: PLQE, PL Lifetime, and Haze

\begin{tabular}{lccc}
\multicolumn{1}{c}{ material } & PLQE $(\%)^{a}$ & PL lifetime $(\mathrm{ns})^{b}$ & Haze $\left(\% \mu \mathrm{m}^{-1}\right)$ \\
$\mathrm{mh}-\mathrm{CN}$ & 13 & 48.5 & \\
$\mathrm{pb}-\mathrm{CN}$ & 5 & 4.2 & $3.8 \pm 0.3$ \\
$\mathrm{pb}-\mathrm{CN}+2 \%$ DMDBS & 5 & & $2.5 \pm 0.3$ \\
${ }^{a}$ Standard deviation from repeated measurements & on identical \\
samples $<0.5 \% .{ }^{b}$ Amplitude-weighted average values, & $\tau_{\mathrm{av}}$ extracted \\
from a fit using a sum of exponential components. PL detection was \\
set at 534 and $521 \mathrm{~nm}$ for mh- and pb-CN, respectively.
\end{tabular}

PLQE is a key material property for light-emitting devices and is defined as the ratio of the number of emitted photons to the number of absorbed photons. Assembled mh-CN is found to exhibit a high PLQE of $13 \%$, whereas a somewhat lower value of $5 \%$ is obtained for pb-CN. These values are substantially higher than the only PLQE reported so far for light-emitting Magnus' salt derivatives, that is, PLQE $=0.2 \%$ obtained for anhydrous $\left[\mathrm{Pt}(\mathrm{bpy})_{2}\right]\left[\mathrm{Pt}(\mathrm{CN})_{4}\right]{ }^{19}$

Room-temperature time-resolved analysis of $\mathrm{PL}$ decay kinetics yielded amplitude-weighted average PL lifetime values, $\tau_{\mathrm{av}}$, of 48.5 and $4.2 \mathrm{~ns}$ for assembled mh- and $\mathrm{pb}-\mathrm{CN}$, respectively (Table 1). (See Figure S12 and Table S6 for PL decay data and details of fitting.) The corresponding radiative decay rates $\left(k_{\mathrm{r}}=\mathrm{PLQE} / \tau_{\mathrm{av}}\right)$ estimated from the data in Table 1 are $2.7 \times 10^{6}$ and $1.2 \times 10^{7} \mathrm{~s}^{-1}$ for $\mathrm{mh}$ - and $\mathrm{pb}-\mathrm{CN}$, respectively. Given these large $k_{\mathrm{r}}$ values, we conclude that the electronic transition responsible for emission cannot be Laporte-forbidden, that is, ligand-field $(\mathrm{d} \rightarrow \mathrm{d})$, in its origin. Furthermore, the obtained values of $\tau_{\mathrm{av}}$ and $k_{\mathrm{r}}$ are comparable with those reported previously for the anhydrous $\left[\mathrm{Pt}(\mathrm{bpy})_{2}\right]$ $\left[\mathrm{Pt}(\mathrm{CN})_{4}\right]$ complex. ${ }^{19}$ On the basis of this similarity of structure and optical characteristics, we tentatively assign emission from TCN-MS derivatives to an allowed transition, most likely $\operatorname{Pt}\left(6 \mathrm{p}_{z} \rightarrow 5 \mathrm{~d}_{\mathrm{z}}{ }^{2}\right),{ }^{19}$ with shorter $(\tau \leq 1 \mathrm{~ns})$ - and longer $(\tau>10 \mathrm{~ns})$-lived emission plausibly corresponding to its spin-allowed and spin-forbidden components, respectively. Further work will be needed to confirm this.

For applications such as luminescent solar concentrators and transparent conductive electrodes (TCEs), a high degree of optical transparency is required, which is typically quantified as "haze." In practical terms, haze is defined as the reduction of perceived image quality of an object viewed through a material specimen because of diffuse scattering of light. Haze was 
measured using the recently developed imaging-based technique, $^{37}$ with the film thickness-normalized values presented in Table 1 . Gratifyingly, the haze of relatively thick $(\sim 1.8 \mu \mathrm{m})$ films of assembled pb-CN is low (6.9 and $4.6 \%$ for neat and nucleated samples, respectively) and comparable to that recorded for thin films of materials intended for applications in, for instance, solar concentrators $(\sim 4 \%)$ and TCEs $(\sim 1 \%))^{38,39}$ The reduction of haze for DMDBSnucleated $\mathrm{pb}-\mathrm{CN}$ is an interesting observation, with further work needed to establish whether this is simply due to elimination of microcracks or if DMDBS indeed enables physical clarification. ${ }^{36}$

\section{DISCUSSION}

Several aspects of the presented results deserve additional comment. First, to what extent is there supporting evidence for the occurrence of assembly of TCN-MS coordination units into quasi-1D polymeric structures via matrix-assisted processing? Given the disklike geometry and ionic nature of the individual coordination units as well as the branched alkyl substituents of $\left[\mathrm{Pt}\left(\mathrm{NH}_{2} R\right)_{4}\right]$ units (Figure 1), the most plausible crystalline packing motif would indeed correspond to $1 \mathrm{D}$ cation/anion stacking into polymerlike structures. At the same time, the mechanical properties of annealed films subjected to swelling stress during PEO removal (Figure 2) are strongly indicative of the presence of macroscopic interlinking within the films. Elsewhere, the results of Raman and IR spectroscopy-particularly the increased relative intensity of $\mathrm{Pt}-\mathrm{C}$ and $\mathrm{Pt}-\mathrm{CN}$ vibrational modes (Figures 5 and $7 b$ ) - highlight crystalline ordering within annealed films. Finally, DSC analysis unambiguously confirms the occurrence of a crystallization transformation for TCN-MS coordination compounds dissolved in PEO upon heating, with the Avrami analysis of isothermal transformation kinetics indicating $1 \mathrm{D}$ crystal growth (Figure 6). Thus, on balance, the formation of quasi-1D TCN-MS inorganic polymers via employed processing is considered to be substantiated by experimental observations.

Second, it is worth outlining the principal solid-state optical properties of TCN-MS inorganic polymers that could be an enabling feature for their applications in optoelectronic devices. These would include the following:

(i) Bright PL with PLQE up to $13 \%$ in first-demonstration samples. (Note that higher values can be expected following a judicious optimization of the solid-state microstructure. ${ }^{40}$ )

(ii) Large Stokes shift up to $1 \mathrm{eV}$ or, if calculated relative to the more prominent absorption feature at $\sim 290 \mathrm{~nm}$, reaching up to $1.9 \mathrm{eV}$ (Figure 3).

(iii) Transparency in the visible spectral range. Notably, the estimated values for the so-called "human perception transmittance" 41 of assembled mh- and pb-CN films reach $98 \%$ for reflection-corrected transmission spectra and the standard D65 illuminant.

Coupled with their solution-processability, TCN-MS derivatives may therefore be promising candidates for applications in thin-film light-emitting devices, the performance of which benefits from reduced degrees of self-absorption of emitted light as enabled by the large Stokes shift. Examples include light-emitting diodes and, particularly, lasers for which minimized self-absorption can substantially reduce lasing thresholds. ${ }^{42}$ Furthermore, their transparency in the visible range and absorption in the ultraviolet (UV) spectral range may be a further asset for potential applications in light management for photovoltaics, for example, as luminescent solar concentrators ${ }^{43,44}$ and downconversion filters, ${ }^{45,46}$ as well as in the more exotic devices such as direct-view augmented reality displays. $^{47}$

Elsewhere, if electrical conductivity of assembled TCN-MS derivatives-expected to be strongly dependent on the solidstate microstructure - can be realized and controlled via, for instance, partial oxidation ${ }^{48}$ or the use of molecular dopants, these materials may find further applications in thermoelectric devices ${ }^{49}$ and transparent conductors. ${ }^{50}$ It also remains to be established whether TCN-MS inorganic polymers, as well as the optoelectronic properties thereof, possess the remarkable stability of MGS derivatives against degradation under exposure to oxygen and water. ${ }^{4}$

\section{CONCLUSIONS}

In summary, we report the synthesis of soluble TCN-MS derivatives with the formula $\left[\mathrm{Pt}\left(\mathrm{NH}_{2} R\right)_{4}\right]\left[\mathrm{Pt}(\mathrm{CN})_{4}\right]$, where $R$ is a solubilizing side-group, as well as processing and characterization thereof. While in solutions, these coordination compounds dissolve on the level of individual ions or ion pairs, matrix-assisted assembly-that is, codissolution with PEO followed by film deposition, thermal annealing at $T \leq 225^{\circ} \mathrm{C}$, and eventual removal of PEO-enables the formation of quasi1D TCN-MS polymeric stacks in solid-state thin films and simultaneously enables bright blue-green PL. The solid-state microstructure and the resulting optical properties of TCN-MS derivatives are shown to be dependent on the specific solubilizing side-groups used as well as the assembly process itself via control of temperature or use of nucleating agents, thereby allowing for further structure-property optimization.

The combination of solution-processability and optical properties of TCN-MS derivatives, such as high transparency in the visible spectral range, PLQE reaching 13\%, and Stokes shifts up to $1 \mathrm{eV}$, make them a highly promising material class in the field of plastic electronics. Future work will aim to examine light-emission characteristics as a function of interplatinum distance using pressure-dependent PL spectroscopy. ${ }^{51}$ Elsewhere, using X-ray scattering to elucidate the intramolecular structure, as well as the length, ${ }^{52}$ of coordination stacks formed via assembly would be advantageous for further development of this class of inorganic polymers.

\section{EXPERIMENTAL SECTION}

Materials. Potassium tetrachloroplatinate $\left(\mathrm{K}_{2}\left[\mathrm{PtCl}_{4}\right]\right.$; lot no. CK0571) and potassium tetracyanoplatinate $\left(\mathrm{K}_{2}[\mathrm{Pt}\right.$ $\left.(\mathrm{CN})_{4}\right]$; lot no. 150383) were purchased from Johnson Matthey, Switzerland. 6-methyl-1-heptylamine ("mh"; 97\%) and 4-phenyl-1-butylamine ("pb"; 98\%) were purchased from Alfa Aesar, Germany; 3,7-dimethly-1-octylamine ("dmoc"; 95\%) was purchased from Fluorochem, UK; 2-ethyl-1hexylamine ("eh"; 98\%) was purchased from Aldrich, Switzerland. PEO (MW $\approx 5 \times 10^{6} \mathrm{~g} \mathrm{~mol}^{-1}$ ) was purchased from Polysciences, Inc., USA. The nucleating agent DMDBS ("Millad 3988") was obtained from Milliken Chemical, Belgium. Unless stated otherwise, all materials were used as received. Details of the solvents used are given in the Supporting Information. 
Synthesis. The representative synthesis of $\mathrm{mh}$ - and $\mathrm{pb}$ substituted TCN-MS compounds is described herein. The synthesis of additional compounds (dmoc- $\mathrm{CN}$ and eh-CN) is reported in the Supporting Information.

Tetrakis (6-methylheptyl-1-amine)platinum(II) Tetracyanoplatinate(II) ("mh-CN"). A solution containing $1100 \mathrm{mg}(2.65 \mathrm{mmol})$ of $\mathrm{K}_{2}\left[\mathrm{PtCl}_{4}\right]$ in $20 \mathrm{~mL}$ of deionized water was heated to $60{ }^{\circ} \mathrm{C}$ under stirring. 6-methylheptyl-1amine $(2.74 \mathrm{~mL}, 21.2 \mathrm{mmol})$ was added to the solution, and the mixture was kept under stirring at $60{ }^{\circ} \mathrm{C}$. After $5 \mathrm{~min}$, the initially red-colored solution turned yellow, and after $30 \mathrm{~min}$, a yellow organic phase and a clear aqueous phase containing dissolved $\mathrm{K}^{+}$and $\mathrm{Cl}^{-}$ions were formed. The two-phase solution was cooled to room temperature after $60 \mathrm{~min}$. A second solution containing $1000 \mathrm{mg}(2.65 \mathrm{mmol})$ of $\mathrm{K}_{2}\left[\mathrm{Pt}(\mathrm{CN})_{4}\right]$ in $10 \mathrm{~mL}$ of deionized water was added to the first solution under stirring. A white precipitate formed immediately and began attaching to the walls of the roundbottomed flask, forming a white ball under movement of the magnetic stirrer. The aqueous part of the solution was decanted, and the flask was dried in vacuum for $2 \mathrm{~h}$. The product was then redispersed in $15 \mathrm{~mL}$ of chloroform at $60^{\circ} \mathrm{C}$ under stirring followed by cooling to room temperature. Adding $40 \mathrm{~mL}$ of ethanol yielded a translucent white dispersion. The product was filtered through a sintered glass funnel (P4, $7.5 \mu \mathrm{m}$ pore diameter), rinsed sequentially with 5 $\mathrm{mL}$ of water and ethanol, and finally dried at $10^{-2}$ mbar. Yield: $1534 \mathrm{mg}, 57 \%$.

Tetrakis(4-phenyl-1-butylamine)platinum(II) Tetracyanoplatinate(II) (" $p b-C N$ "). A solution containing 440 $\mathrm{mg}(1.06 \mathrm{mmol})$ of $\mathrm{K}_{2}\left[\mathrm{PtCl}_{4}\right]$ in $8 \mathrm{~mL}$ of deionized water was stirred for $5 \mathrm{~min}$ before adding $1.01 \mathrm{~mL}(6.78 \mathrm{mmol})$ of 4 phenyl-1-butylamine. A color change from red to orange/ yellow was observed as the solution was stirred at room temperature for $30 \mathrm{~min}$. The solution was then heated to 60 ${ }^{\circ} \mathrm{C}$ under stirring, turning its color light-yellow. After cooling to room temperature, a two-phase solution was obtained: a yellow organic phase and an opaque aqueous phase. A second solution containing $400 \mathrm{mg}(1.06 \mathrm{mmol})$ of $\mathrm{K}_{2}\left[\mathrm{Pt}(\mathrm{CN})_{4}\right]$ in 4 $\mathrm{mL}$ of deionized water was added to the first solution under stirring, followed by sequential addition of hexane $(18 \mathrm{~mL})$, toluene $(6 \mathrm{~mL})$, and ethanol $(2 \mathrm{~mL})$. The phase containing the product turned translucent white as expected. After filtering the mixture through a sintered glass funnel $(\mathrm{P} 4,7.5 \mu \mathrm{m}$ pore diameter), the obtained product was washed with $2 \mathrm{~mL}$ of deionized water and dried under vacuum for $2 \mathrm{~h}$. The product was then redispersed in $6 \mathrm{~mL}$ of chloroform and stirred for 30 min, followed by addition of $8 \mathrm{~mL}$ of ethanol. The dispersion was filtered (as above), washed with $2 \mathrm{~mL}$ of ethanol, and finally dried at $10^{-2}$ mbar. Yield: $849 \mathrm{mg}, 73 \%$.

Thin Film Fabrication. TCN-MS derivatives were dissolved in DMF (17 wt \% for mh-, pb-, and eh-CN; 6\% for dmoc-CN). To the solutions, 2 wt \% PEO was added relative to the amount of DMF. Solutions were spin-coated onto fused silica substrates (Spectrosil B, UQG Optics) at $1000 \mathrm{rpm}$, with the solutions, and the substrates were preheated on a hotplate at $95{ }^{\circ} \mathrm{C}$. The matrix-assisted assembly of TCN-MS coordination units involved heating the as-spincoated films from room temperature to a selected assembly temperature, $T_{\mathrm{A}}$, annealing for $20 \mathrm{~min}$, and cooling to room temperature. All thermal treatments were performed under nitrogen atmosphere following complete removal of the solvent by desiccation. The films were then immersed in water at $75{ }^{\circ} \mathrm{C}$ for $90 \mathrm{~s}$, which resulted in maximally complete removal of PEO, as confirmed by the absence of its characteristic Raman and IR spectral features for the obtained TCN-MS films. The resulting thicknesses of assembled films were $\sim 1.8 \mu \mathrm{m}$ (mh- and pb-CN) and $\sim 1 \mu \mathrm{m}$ (dmoc-CN).

Characterization. As-Synthesized Compounds. Elemental analysis was performed at the Microanalytic Laboratory of the Laboratory of Organic Chemistry at ETH Zürich. IR spectroscopy of the as-synthesized compounds (pelletized with $\mathrm{KBr}$ ) was performed on a Bruker VERTEX 70 Fourier transform infrared instrument. UV-visible (UV-vis) absorption spectra of TCN-MS solutions ( $0.2 \mathrm{wt} \%$ in DMF) were recorded using a Jasco V-670 spectrophotometer. SAXS experiments on TCN-MS and MGS derivatives (1 wt \% solutions) were performed using a Rigaku MicroMax- $002^{+}$ equipped with a microfocused beam $(40 \mathrm{~W}, 45 \mathrm{kV}, 0.88 \mathrm{~mA})$, with the $\lambda_{\mathrm{CuK} \alpha}=0.15418 \mathrm{~nm}$ radiation collimated by three pinhole collimators $(0.4,0.3$, and $0.8 \mathrm{~mm})$. The SAXS intensities were collected by a two-dimensional Triton-200 gas-filled X-ray detector (20 cm diameter, $200 \mu \mathrm{m}$ resolution). An effective scattering vector range of $0.1 \mathrm{~nm}^{-1}<q<2 \mathrm{~nm}^{-1}$ was obtained, where $q$ is the scattering wave vector defined as $q$ $=4 \pi \sin \theta / \lambda_{\mathrm{CuK} \alpha}$ with a scattering angle of $2 \theta$.

Thin Films. Unless stated otherwise, all thin-film characterizations were carried out following PEO removal. The film thickness was measured using a DektakXT profilometer (Bruker). IR spectra were recorded on a Tensor 27 FTIR spectrometer (Bruker) equipped with an attenuated total reflectance cell. A WITec Alpha 300RA instrument was used for reflected light microscopy, confocal PL microscopy $\left(\lambda_{\text {ex }}=\right.$ $355 \mathrm{~nm})$, and Raman spectroscopy $\left(\lambda_{\mathrm{ex}}=785 \mathrm{~nm}\right)$ analyses. Transmitted light and fluorescence microscopy (UV excitation) were performed using a BX51 instrument (Olympus) equipped with a U-RFL-T mercury lamp accessory. UV-vis absorption spectra were recorded using a UV-2600 spectrophotometer (Shimadzu) equipped with an integrating sphere attachment, allowing the absorption spectra to be corrected for reflection and scattering losses. PL and PLE spectra were recorded using a Jasco FP-8500 spectrofluorometer. PLQE measurements as well as absorption/PL analysis during sequential annealing of TCN-MS/PEO blend films were performed using a HORIBA Scientific FluoroMax-4 spectrofluorometer equipped with a Quanta- $\varphi$ integrating sphere attachment. PLQE analysis was carried out following the method described in ref 40 using excitation at $\lambda_{\text {ex }}=360$ $\mathrm{nm}$; no self-absorption correction was required given the large Stokes shift for TCN-MS derivatives. PL lifetime measurements were performed using the time-correlated single photon counting (TCSPC) technique. The PL emitted by the samples was dispersed by a grating inside a spectrometer (SP2500, Acton Research) and subsequently detected with a PMA hybrid photomultiplier assembly (Hamamatsu Photonics; transit time spread $<50 \mathrm{ps}$ ). Two different excitation/data acquisition configurations were employed to monitor the picosecond-nanosecond and nanosecond-microsecond time domains. PL decay measurements in the short time domain involved excitation with a $405 \mathrm{~nm}$ picosecond diode laser (PDL 828 PicoQuant Sepia; 50 ps pulse duration, 2.5-80 $\mathrm{MHz}$ adjustable repetition rate) and acquisition with a PicoQuant HydraHarp-400 TCSPC system. Analogous measurements in the long-time domain involved excitation with a $355 \mathrm{~nm}$ passively Q-switched Nd:YAG laser (TEEM Photonics; $0.3 \mathrm{~ns}$ pulse duration, $10-1000 \mathrm{~Hz}$ tunable 
repetition rate) and acquisition with a TimeHarp 260 TCSPC board. FluoFit (PicoQuant) software was used to fit the data; details are given in the Supporting Information. Analysis of haze was performed using an imaging-based method described in ref 37, currently in development with an industrial instrumentation manufacturer. The procedure was identical to that in ref 37, with the exception of using a longpass filter $(\lambda$ $>500 \mathrm{~nm}$ ) for the illumination light to avoid any distorting effects due to excitation of PL. Whereas haze is generally measured using ASTM D1003 haze-meter instruments, ${ }^{53}$ the employed imaging-based method was deemed more accurate given that (i) specifically, contact haze is analyzed locally over (ii) small, $\sim 8 \mathrm{~mm}^{2}$, sample areas with the possibility of using (iii) additional optical elements such as a longpass filter.

Thermal analysis. DSC was performed using a MettlerToledo DSC 2 instrument calibrated using indium standards. Powder mixtures of selected TCN-MS compounds with PEO (3:1 wt/wt ratio) were prepared using a mortar and pestle, loaded into low-pressure aluminium pans, and heated at $75{ }^{\circ} \mathrm{C}$ for $30 \mathrm{~min}$ to aid dissolution. All measurements were carried out under a constant nitrogen flow.

DFT Calculations. DFT calculations were performed for $\left[\mathrm{Pt}\left(\mathrm{NH}_{2} \mathrm{CH}_{3}\right)_{4}\right]\left[\mathrm{Pt}(\mathrm{CN})_{4}\right]_{n}$, imposing $\mathrm{C}_{4}$ symmetry, using the CAM-B3LYP functional; the $6-311 \mathrm{G}^{*}$ basis set LANL2DZ basis set for Pt augmented with 6d functions was utilized in all cases, as defined in the Gaussian program package. ${ }^{54}$

\section{ASSOCIATED CONTENT}

\section{S Supporting Information}

The Supporting Information is available free of charge on the ACS Publications website at DOI: 10.1021/acsomega.9b00942.

Synthesis and elemental analysis; characterization of dissolved TCN-MS derivatives; optical microscopy of dmoc-CN films; topography of assembled films; confocal PL microscopy of TCN-MS films; Raman spectroscopy; intrachain structure and bonding; nucleation of TCN-MS complexes using DMDBS; and timeresolved PL spectroscopy (PDF)

\section{AUTHOR INFORMATION}

\section{Corresponding Authors}

*E-mail: aperevedentsev@icmab.es (A.P.).

*E-mail: fabio.bargardi@mat.ethz.ch (F.L.B.).

\section{ORCID}

Aleksandr Perevedentsev: 0000-0003-0146-3560

Nathan J. Cheetham: 0000-0002-2259-1556

Johannes Gierschner: 0000-0001-8177-7919

Raffaele Mezzenga: 0000-0002-5739-2610

Juan Cabanillas-Gonzalez: 0000-0002-9926-3833

\section{Author Contributions}

${ }_{\mathbb{T}}$ A.P. and F.L.B. contributed equally to this work.

\section{Funding}

The work in Barcelona was financially supported by the Ministerio de Economía y Competitividad of Spain through the Severo Ochoa Programme for Centres of Excellence in R\&D (SEV-2015-0496) and project MAT2015-70850-P and the European Research Council (ERC) under grant agreement no. 648901. The work in Madrid and Valencia was supported by the Spanish Ministerio de Economía y Competitividad (MINECO-FEDER project CTQ2017-87054); the work in
Madrid was further supported by the Severo Ochoa Programme for Centers of Excellence in R\&D program of the MINECO (SEV-2016-0686) and by the Campus of International Excellence (CEI) UAM + CSIC.

\section{Notes}

The authors declare no competing financial interest.

\section{ACKNOWLEDGMENTS}

The authors are indebted to Paul Smith (ETH Zürich) as well as Alejandro Goñi and Adrian Francisco (ICMAB) for useful discussions. A.P. expresses his gratitude to Xingyuan Shi (Imperial College London) and Daniel Kremer (Universität Bayreuth) for hosting his research visits.

\section{REFERENCES}

(1) Magnus, G. Ueber einige Verbindungen des Platinchlorrs. Ann. Phys. 1828, 90, 239-242.

(2) Atoji, M.; Richardson, J. W.; Rundle, R. E. On the Crystal Structures of the Magnus Salts, $\mathrm{Pt}\left(\mathrm{NH}_{3}\right)_{4} \mathrm{PtCl}_{4}$. J. Am. Chem. Soc. 1957, 79, 3017-3020.

(3) Miller, J. R. 112. The metal-metal interaction in Magnus's green salt and related compounds. J. Chem. Soc. 1965, 0, 713-720.

(4) Caseri, W. R.; Chanzy, H. D.; Feldman, K.; Fontana, M.; Smith, P.; Tervoort, T. A.; Goossens, J. G. P.; Meijer, E. W.; Schenning, A. P. H. J.; Dolbnya, I. P.; Debije, M. G.; de Haas, M. P.; Warman, J. M.; Friend, R. H.; Sirringhaus, H.; Stutzmann, N.; Stutzmann, N. "(Hot)Water-Proof”, Semiconducting, Platinum-based Chain Structures: Processing, Products, and Properties. Adv. Mater. 2003, 15, 125-129.

(5) Debije, M. G.; de Haas, M. P.; Warman, J. M.; Fontana, M.; Stutzmann, N.; Caseri, W. R.; Smith, P.; Smith, P. Highly Anisotropic Opto-electronic Properties of Aligned Films of Self-Assembled Platinum Molecular Wires. Adv. Mater. 2003, 15, 896-899.

(6) Caseri, W. Derivatives of Magnus' Green Salt. Platinum Met. Rev. 2004, 48, 91-100.

(7) Debije, M. G.; de Haas, M. P.; Fontana, M.; Stutzmann, N.; Kristiansen, M.; Caseri, W. R.; Smith, P.; Hoffmann, S.; Sølling, T. I.; Sølling, T. I. Optoelectronic Properties of Quasi-Linear, SelfAssembled Platinum Complexes: Pt-Pt Distance Dependence. Adv. Funct. Mater. 2004, 14, 323-328.

(8) Kim, E.-G.; Schmidt, K.; Caseri, W. R.; Kreouzis, T.; StingelinStutzmann, N.; Brédas, J.-L. Magnus' Green Salt Revisited: Impact of Platinum-Platinum Interactions on Electronic Structure and Carrier Mobilities. Adv. Mater. 2006, 18, 2039-2043.

(9) Hendon, C. H.; Walsh, A.; Akiyama, N.; Konno, Y.; Kajiwara, T.; Ito, T.; Kitagawa, H.; Sakai, K. One-dimensional Magnus-type Platinum Double Salts. Nat. Commun. 2016, 7, 11950.

(10) Bradley, D. D. C. Organic Electronics and Photonics: Concluding Remarks. Faraday Discuss. 2014, 174, 429-438.

(11) Heeger, A. J. Semiconducting Polymers: the Third Generation. Chem. Soc. Rev. 2010, 39, 2354-2371.

(12) Brenner, T. M.; Egger, D. A.; Kronik, L.; Hodes, G.; Cahen, D. Hybrid Organic-Inorganic Perovskites: Low-cost Semiconductors with Intriguing Charge-Transport Properties. Nat. Rev. Mater. 2016, $1,15007$.

(13) Sutherland, B. R.; Sargent, E. H. Perovskite Photonic Sources. Nat. Photonics 2016, 10, 295-302.

(14) Allendorf, M. D.; Schwartzberg, A.; Stavila, V.; Talin, A. A. A Roadmap to Implementing Metal-Organic Frameworks in Electronic Devices: Challenges and Critical Directions. Chem. - Eur. J. 2011, 17, 11372-11388.

(15) Hendon, C. H.; Tiana, D.; Walsh, A. Conductive MetalOrganic Frameworks and Networks: Fact or Fantasy? Phys. Chem. Chem. Phys. 2012, 14, 13120-13132.

(16) Qiu, L.; Ono, L. K.; Qi, Y. Advances and Challenges to the Commercialization of Organic-Inorganic Halide Perovskite Solar Cell Technology. Mater. Today Energy 2018, 7, 169-189. 
(17) Bremi, J.; Brovelli, D.; Caseri, W.; Hähner, G.; Smith, P.; Tervoort, T. From Vauquelin's and Magnus' Salts to Gels, Uniaxially Oriented Films, and Fibers: Synthesis, Characterization, and Properties of Tetrakis(1-aminoalkane)metal(II) Tetrachlorometalates(II). Chem. Mater. 1999, 11, 977-994.

(18) Fontana, M.; Chanzy, H.; Caseri, W. R.; Smith, P.; Schenning, A. P. H. J.; Meijer, E. W.; Gröhn, F. A Soluble Equivalent of the Supramolecular, Quasi-One-Dimensional, Semiconducting Magnus' Green Salt. Chem. Mater. 2002, 14, 1730-1735.

(19) Houlding, V. H.; Frank, A. J. Cooperative Excited-State Behavior in Platinum(II) Magnus-Type Double-Salt Materials. Active and Inactive Photosensitizers for $\mathrm{H}_{2}$ Production in Aqueous Suspension. Inorg. Chem. 1985, 24, 3664-3668.

(20) Daws, C. A.; Exstrom, C. L.; Sowa, J. R., Jr.; Mann, K. R. "Vapochromic" Compounds as Environmental Sensors. 2. Synthesis and Near-Infrared and Infrared Spectroscopy Studies of [Pt(arylisocyanide) $\left.{ }_{4}\right]\left[\mathrm{Pt}(\mathrm{CN})_{4}\right]$ upon Exposure to Volatile Organic Compound Vapors. Chem. Mater. 1997, 9, 363-368.

(21) Drew, S. M.; Janzen, D. E.; Buss, C. E.; MacEwan, D. I.; Dublin, K. M.; Mann, K. R. An Electronic Nose Transducer Array of Vapoluminescent Platinum(II) Double Salts. J. Am. Chem. Soc. 2001, 123, 8414-8415.

(22) Bremi, J.; Caseri, W.; Smith, P. A New Compound Derived from Magnus' Green Salt: Solid State Structure and Evidence for Platinum Chains in Solution. J. Mater. Chem. 2001, 11, 2593-2596.

(23) Cradwick, M. E.; Hall, D.; Phillips, R. K. The Crystal Structures of Compounds Analogous to Magnus' Green Salt. Acta Crystallogr., Sect. B: Struct. Crystallogr. Cryst. Chem. 1971, 27, 480-484.

(24) Raman, A.; Farris, R. J.; Lesser, A. J. Effect of Stress State and Polymer Morphology on Environmental Stress Cracking in Polycarbonate. J. Appl. Polym. Sci. 2003, 88, 550-564.

(25) Braendle, A.; Perevedentsev, A.; Cheetham, N. J.; Stavrinou, P. N.; Schachner, J. A.; Mösch-Zanetti, N. C.; Niederberger, M.; Caseri, W. R. Homoconjugation in Poly(Phenylene Methylene)s: A Case Study of Non- $\pi$-Conjugated Polymers with Unexpected Fluorescent Properties. J. Polym. Sci., Part B: Polym. Phys. 2017, 55, 707-720.

(26) Braendle, A.; Perevedentsev, A.; Cheetham, N. J.; Stavrinou, P. N.; Schachner, J. A.; Mösch-Zanetti, N. C.; Niederberger, M.; Caseri, W. Polymers with Exceptional Photoluminescence by Homoconjugation. Chimia Int. J. Chem. 2017, 71, 733.

(27) Gam, S.; Corlu, A.; Chung, H.-J.; Ohno, K.; Hore, M. J. A.; Composto, R. J. A Jamming Morphology Map of Polymer Blend Nanocomposite Films. Soft Matter 2011, 7, 7262-7268.

(28) You, J.; Zhang, S.; Huang, G.; Shi, T.; Li, Y. Solvent Annealing Induced Phase Separation and Dewetting in PMMA/SAN Blend Film: Film Thickness and Solvent Dependence. J. Chem. Phys. 2013, 138, 244907.

(29) Perevedentsev, A.; Stavrinou, P. N.; Smith, P.; Bradley, D. D. C. Solution-Crystallization and Related Phenomena in 9,9-DialkylFluorene Polymers. II. Influence of Side-Chain Structure. J. Polym. Sci., Part B: Polym. Phys. 2015, 53, 1492-1506.

(30) Sperling, L. H. Introduction to Physical Polymer Science; Wiley, 2006.

(31) Mühle, C.; Nuss, J.; Jansen, M. Synthesis and Crystal Structure of the Partially Oxidized Cyanoplatinates $\mathrm{Rb}_{1.75}\left[\mathrm{Pt}(\mathrm{CN})_{4}\right] \cdot 1.25 \mathrm{H}_{2} \mathrm{O}$ and $\mathrm{Cs}_{1.75}\left[\mathrm{Pt}(\mathrm{CN})_{4}\right] \cdot 0.5 \mathrm{H}_{2} \mathrm{O}$. Z. Anorg. Allg. Chem. 2013, 639, 479484.

(32) Martin, C. M.; Guha, S.; Chandrasekhar, M.; Chandrasekhar, H. R.; Guentner, R.; Scanduicci de Freitas, P.; Scherf, U. Hydrostatic Pressure Dependence of the Luminescence and Raman Frequencies in Polyfluorenes. Phys. Rev. B: Condens. Matter Mater. Phys. 2003, 68, 115203.

(33) Lorenzo, A. T.; Arnal, M. L.; Albuerne, J.; Müller, A. J. DSC Isothermal Polymer Crystallization Kinetics Measurements and the Use of the Avrami Equation to Fit the Data: Guidelines to Avoid Common Problems. Polym. Test. 2007, 26, 222-231.

(34) Triggs, N. E.; Valentini, J. J. An Investigation of Hydrogen Bonding In Amides Using Raman Spectroscopy. J. Phys. Chem. 1992, 96, 6922-6931.
(35) Ling, Y.; Xie, W. C.; Liu, G. K.; Yan, R. W.; Wu, D. Y.; Tang, J. The Discovery of the Hydrogen Bond from p-Nitrothiophenol by Raman spectroscopy: Guideline for the Thioalcohol Molecule Recognition Tool. Sci. Rep. 2016, 6, 31981.

(36) Kristiansen, M.; Werner, M.; Tervoort, T.; Smith, P.; Blomenhofer, M.; Schmidt, H.-W. The Binary System Isotactic Polypropylene/Bis(3,4-dibenzilidene) Sorbitol: Phase Behavior and Optical Properties. Macromolecules 2003, 36, 5150-5156.

(37) Busato, S.; Perevedentsev, A. A Simple Imaging-Based Technique for Quantifying Haze and Transmittance of Materials. Polym. Eng. Sci. 2017, 58, 345-352.

(38) Menamparambath, M. M.; Ajmal, C. M.; Kim, K. H.; Yang, D.; Roh, J.; Park, H. C.; Kwak, C.; Choi, J.-Y.; Baik, S. Silver Nanowires Decorated with Silver Nanoparticles for Low-haze Flexible Transparent Conductive Films. Sci. Rep. 2015, 5, 16371.

(39) Vasiliev, M.; Alghamedi, R.; Nur-E-Alam, M.; Alameh, K. Photonic Microstructures for Energy-Generating Clear Glass and Netzero Energy Buildings. Sci. Rep. 2016, 6, 31831.

(40) Perevedentsev, A.; Chander, N.; Kim, J.-S.; Bradley, D. D. C. Spectroscopic Properties of Poly(9,9-dioctylfluorene) Thin Films Possessing Varied Fractions of $\beta$-Phase Chain Segments: Enhanced Photoluminescence Efficiency via Conformation Structuring. J. Polym. Sci., Part B: Polym. Phys. 2016, 54, 1995-2006.

(41) Ameri, T.; Dennler, G.; Waldauf, C.; Azimi, H.; Seemann, A.; Forberich, K.; Hauch, J.; Scharber, M.; Hingerl, K.; Brabec, C. J. Fabrication, Optical Modeling, and Color Characterization of Semitransparent Bulk-Heterojunction Organic Solar Cells in an Inverted Structure. Adv. Funct. Mater. 2010, 20, 1592-1598.

(42) Li, W.; Zhang, J.; Zheng, Y.; Chen, G.; Cai, M.; Wei, B. The Energy Transfer Mechanism of a Photoexcited and Electroluminescent Organic Hybrid Thin Film of Blue, Green, and Red Laser Dyes. Nanoscale Res. Lett. 2015, 10, 194.

(43) Goetzberger, A.; Greube, W. Solar Energy Conversion with Fluorescent Collectors. Appl. Phys. 1977, 14, 123-139.

(44) Saraidarov, T.; Levchenko, V.; Grabowska, A.; Borowicz, P.; Reisfeld, R. Non-self-absorbing Materials for Luminescent Solar Concentrators (LSC). Chem. Phys. Lett. 2010, 492, 60-62.

(45) Huang, X. Y.; Wang, J. X.; Yu, D. C.; Ye, S.; Zhang, Q. Y.; Sun, X. W. Spectral Conversion for Solar Cell Efficiency Enhancement using YVO4:Bi3+, Ln3+ (Ln=Dy, Er, Ho, Eu, Sm, and $\mathrm{Yb}$ ) Phosphors. J. Appl. Phys. 2011, 109, 113526.

(46) Engmann, S.; Machalett, M.; Turkovic, V.; Rösch, R.; Rädlein, E.; Gobsch, G.; Hoppe, H. Photon Recycling Across a Ultravioletblocking Layer by Luminescence in Polymer Solar Cells. J. Appl. Phys. 2012, 112, 034517.

(47) Malinowski, P. E.; Ke, T.-H.; Nakamura, A.; Liu, Y.-H.; Vander Velpen, D.; Vandenplas, E.; Papadopoulos, N.; Kronemeijer, A. J.; van der Steen, J.-L.; Steudel, S.; Kuo, C.-C.; Huang, Y.-Y.; Chen, Y.-H.; Yeh, M.-H.; Gelinck, G.; Heremans, P. High Resolution Photolithography for Direct View Active Matrix Organic Light-emitting Diode Augmented Reality Displays. J. Soc. Inf. Disp. 2018, 26, 128136.

(48) Myllynen, S.; Wasberg, M. High Electrical Conductivity for the Partially Oxidised d $\mathrm{d}^{8} \mathrm{Ru}-\mathrm{Ru}$ Bonded Chain $\left[\mathrm{Ru}(\mathrm{bpy})(\mathrm{CO})_{2}\right]_{\mathrm{n}}$ (bpy = 2,2'-bipyridine) and its Wide Range Redox Control. Electrochem. Commun. 2009, 11, 1453-1456.

(49) Sun, Y.; Sheng, P.; Di, C.; Jiao, F.; Xu, W.; Qiu, D.; Zhu, D. Organic Thermoelectric Materials and Devices Based on $p$ - and $n$ Type Poly(metal 1,1,2,2-ethenetetrathiolate)s. Adv. Mater. 2012, 24, 932-937.

(50) Carpenter, J. A.; Dshemuchadse, J.; Busato, S.; Bräunlich, I.; Pöthig, A.; Caseri, W. Tetrakis(4-amino-1,2,4-triazole)platinum(II) Salts: Synthesis, Crystal Structures, and Properties. Z. Anorg. Allg. Chem. 2014, 640, 724-732.

(51) Stock, M.; Yersin, H. High Pressure Tuning of Optical Transitions in $\mathrm{Mg}\left[\mathrm{Pt}(\mathrm{CN})_{4}\right] \cdot 7 \mathrm{H}_{2} \mathrm{O}$. Solid State Commun. 1978, 27, $1305-1308$

(52) Bräunlich, I.; Sánchez-Ferrer, A.; Bauer, M.; Schepper, R.; Knüsel, P.; Dshemuchadse, J.; Mezzenga, R.; Caseri, W. Polynuclear 
Iron(II)-Aminotriazole Spincrossover Complexes (Polymers) in Solution. Inorg. Chem. 2014, 53, 3546-3557.

(53) ASTM D 1003-13. Standard Test Method for Haze and Luminous Transmittance of Transparent Plastics, 2013.

(54) Frisch, M. J. Gaussian 16, Revision A.03; Gaussian, Inc.: Wallingford CT, 2016. 